\title{
Analysis of the Current State of the Processes of Hybrid Laser-Plasma Welding
}

\author{
Volodymyr Korzhyk 1, 2, a, Oleksandr Bushma, b, Vladyslav Khaskin ${ }^{1,2, c}$, \\ Chunlin Dong ${ }^{1, d}$, Volodymyr Sydorets ${ }^{1,2, e}$ \\ ${ }^{1}$ Guangdong Welding Institute (E.O. Paton Chinese-Ukrainian Welding Institute) \\ 363 Changxing Road, Tian He, Guangzhou City, China \\ ${ }^{2}$ E. O. Paton Electric Welding Institute of the National Academy of Science of Ukraine \\ 11, K. Malevich Str., Kiev, 03150, Ukraine \\ avnkorzhyk@gmail.com, boffice@paton.kiev.ua, ${ }^{\mathrm{a}}$ khaskin@ua.fm, \\ ddchunlin@hotmail.com, 'sydorvn@gmail.com
}

Keywords: Hybrid technologies, Laser-plasma welding, Process schematic, Laser radiation, Plasma, Application prospects

\begin{abstract}
The paper presents brief retrospective of progress and state-of-the-art of hybrid laser-plasma welding (HLPW). It is shown that the main objectives of HLPW include not only plasma-arc heating of item metal to increase its absorptivity, but also modification of welding thermal cycle to lower the rate of cooling after welding. This allows lowering the content of brittle structures prone to fracture in service. Moreover, presence of plasma-arc component of the process allows lowering the requirements to quality of fit-up of the butts to be welded, compared to laser welding. Prospects for introduction of HLPW into industry are related to its cost and technological advantages.
\end{abstract}

\section{Introduction}

Hybrid welding is a process which uses two heat sources, acting simultaneously on the item being welded (within a common heating zone). The main feature of this welding process is complementation and enhancement of the impact of each of the applied sources. In the case of hybrid laser-plasma welding (HLPW), the maximum impact is achieved at manifestation of the so-called synergic effect [1]. This effect consists in non- additivity of the results of impact of each of the heat sources, compared to the result of their joint action. In particular, the volume of metal, molten in hybrid welding, as a rule, exceeds the sum of metal volumes molten separately by each of the energy sources, making up the hybrid process. Otherwise, welding is usually regarded as combined, and not hybrid.

A paper published in 1979 on combining non- consumable electrode (TIG) arc with laser welding is taken to be one of the first works on hybrid welding [2]. A more detailed work by Prof. Steen (Great Britain) was published immediately after it in 1980 [3]. He already has several patents in this field (for instance, [4]). After publications by W.M. Steen, hybrid laser processes began to be studied in the majority of industrialized countries of the world.

\section{Basic Schemes of Hybrid Welding Processes}

$\mathrm{CO}_{2}$-lasers with $10.6 \mu \mathrm{m}$ wave length were the first to be applied in hybrid welding processes, as they had high power and were easy to maintain. This type of lasers is still used [5, 6].

Then Nd:YAG-lasers began to be ever wider introduced [7]. One of the main advantages of this laser type is shorter wavelength $(1.06 \mu \mathrm{m})$, at which an increase of metal absorptivity and, therefore, of effective efficiency of the welding process, is observed. Recently introduced into mass production disc and fiber lasers are actively applied now in hybrid welding processes [8, 9]. Their application effectiveness is associated with a higher efficiency (25-35\%) of these systems that also promotes a higher effective efficiency of welding. 
As a rule, in HLPW the focused laser beam is directed along a normal to the surface of item being welded (Fig. 1) [10, 11], or at a small angle to it (up to $10^{\circ}$ ) (Fig. 2) [12]. In terms of design, the laser-plasma welding head can consist of separate elements - laser focusing system and plasmatron, or it can be integrated into a common casing (Fig. 3) [13]. Plasma torch is inclined at a certain (minimum possible) angle to the axis of the focused laser beam (Fig. 4) [14]. Filler wire can be fed coaxially with the plasma arc, towards it, or it may not be fed at all. Laser beam with a high power density and arc plasma with high-energy efficiency interact simultaneously in the weld pool area. To enhance the effect of such interaction, they can be supplied to the parts being welded through a common nozzle (Fig. 5) [15]. In all the cases the laser beam can be located relative to plasma behind or ahead along the welding direction.

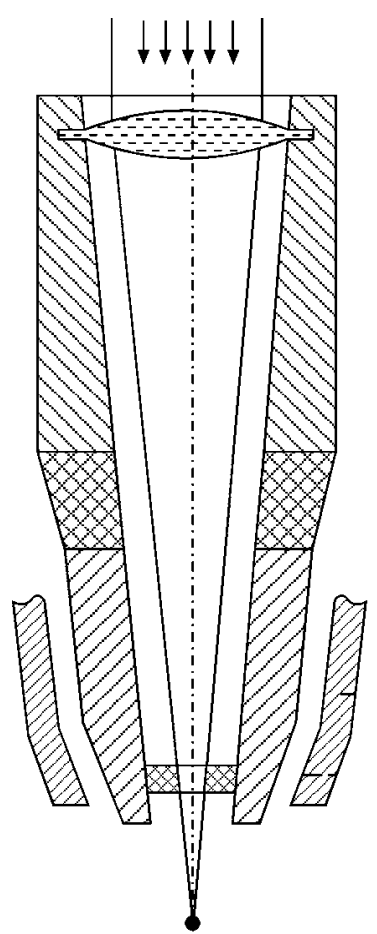

(a) Hollow cathode [10]

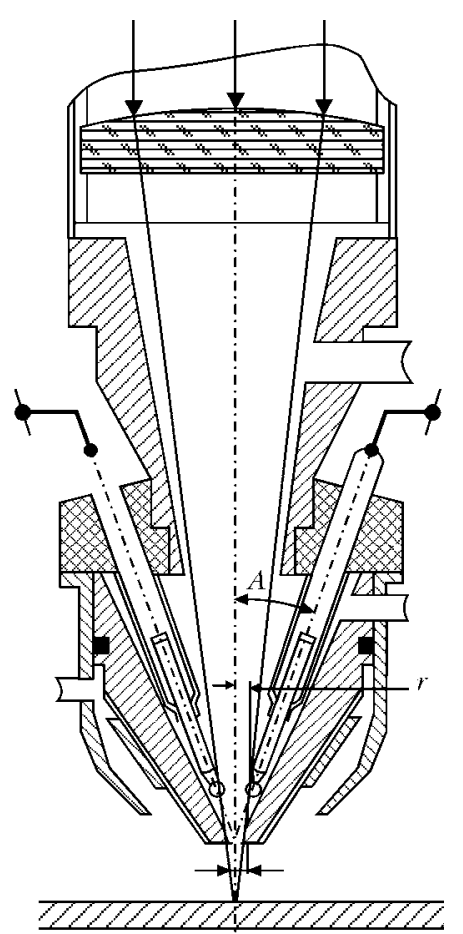

(b) Inclined cathodes located symmetrically relative to laser beam axis [11]

Fig. 1 Design of plasma torches allowing laser radiation to be fed normal to the surface of item being welded.

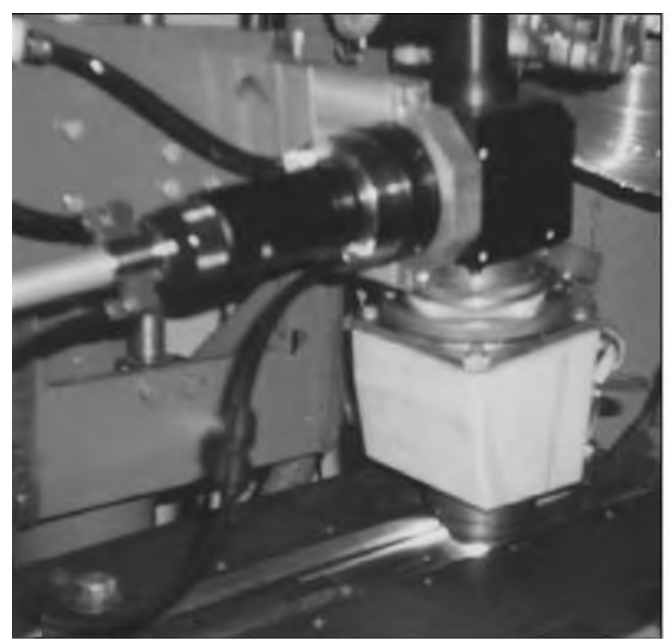

(a) Appearance

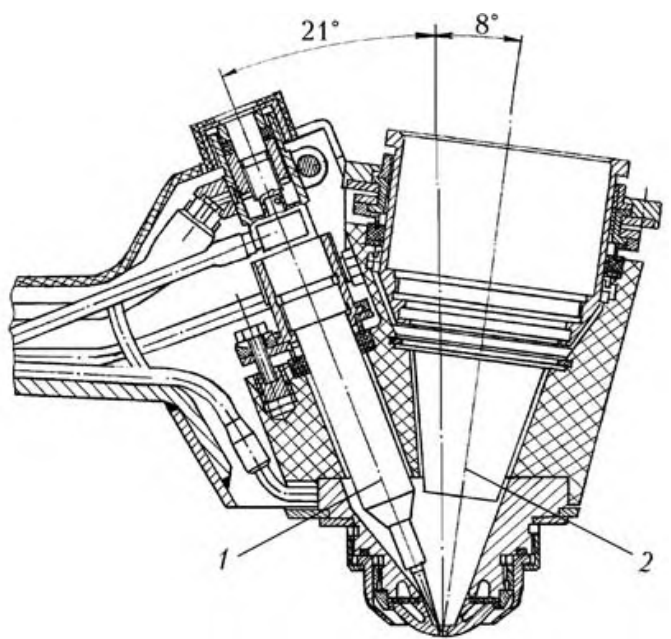

(b) Schematic

Fig. 2 Integrated plasmatron for HLPW [12]: 1 - cathode axis; 2 - focused laser beam axis. 


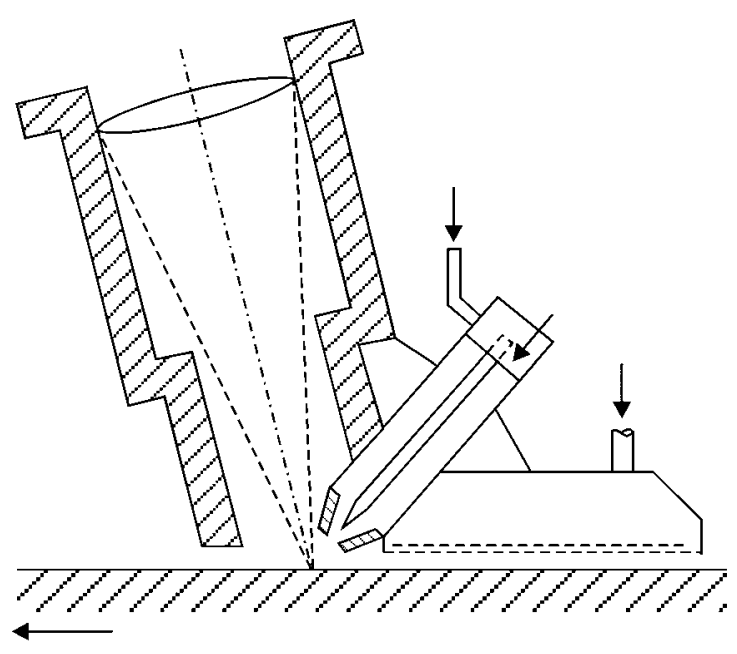

(a) Laser focusing system and the laser torch are used separately

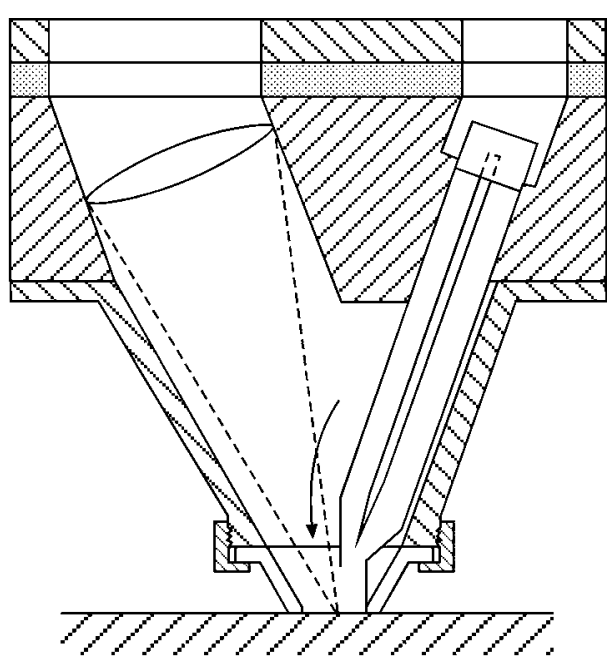

(b) Laser focusing system and the laser torch are integrated in the common casing

Fig. 3 Design of HLPW heads [13].

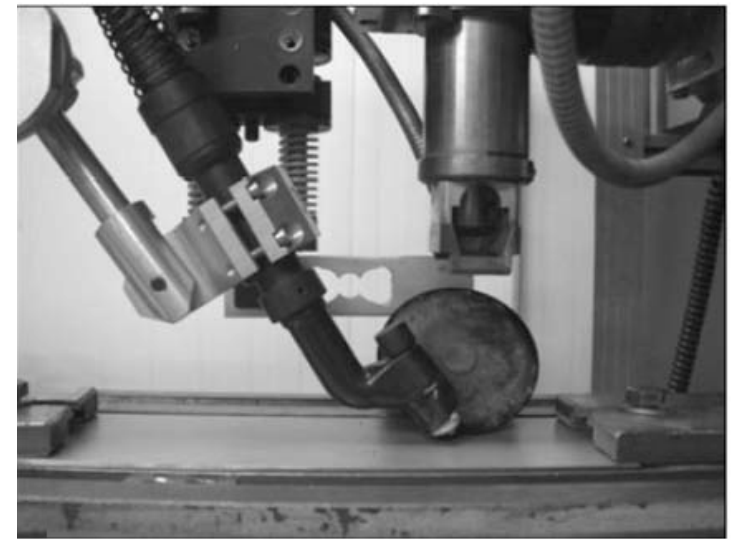

(a) Appearance of HLPW head

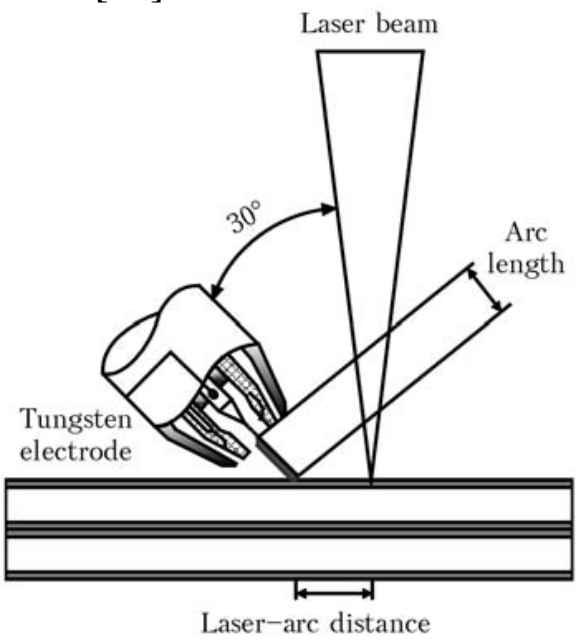

(b) Process technological schematic

Fig. 4 Process of HLPW with inclined position of plasma torch allowing the distance between the plasma and laser beam to be measured [14].

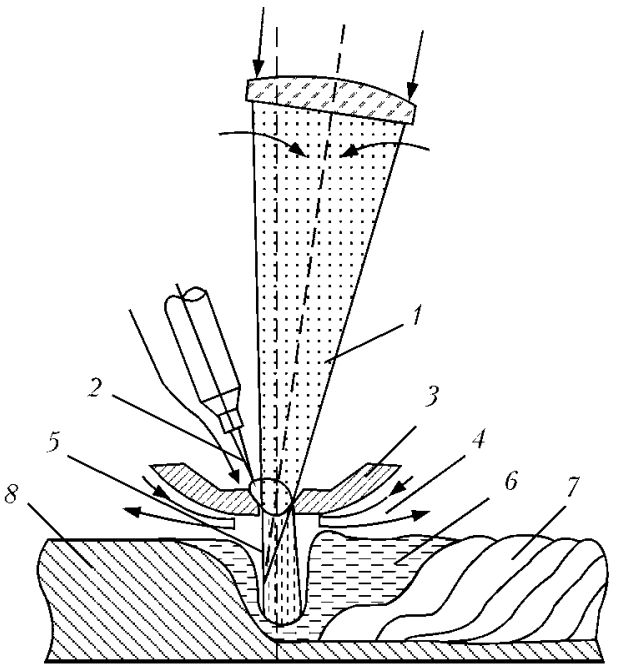

(a) Plasma torch location ahead of the laser beam

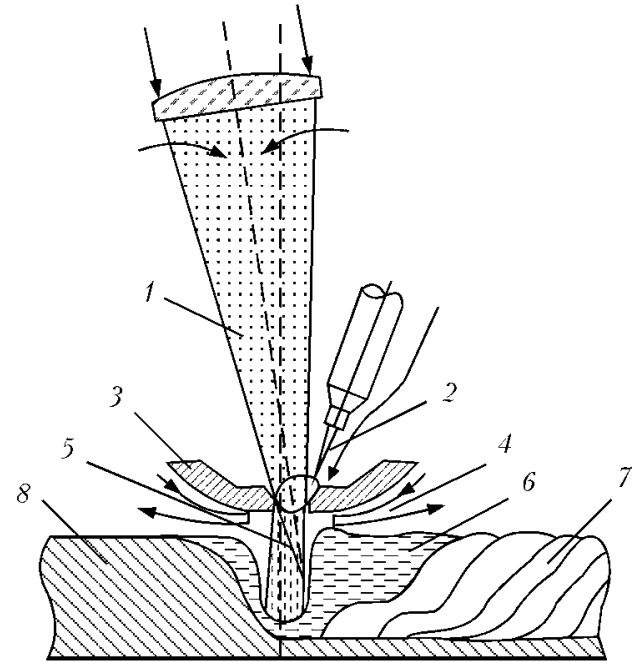

(b) Plasma torch location behind of the laser beam

Fig. 5 Schematics of the HLPW process [15]: 1 - focused laser radiation; 2 - nonconsumable electrode; 3 - plasma-forming nozzle; 4 - shielding gas; 5 - plasma discharge; 6 - weld pool; 7 - weld metal; 8 - base metal. 
Let us consider in greater detail the advantages and disadvantages of laser-plasma welding process schematics shown in Fig. 1-5.

\section{Advantages and Disadvantages of Laser-Plasma Welding Processes}

According to the method proposed in [16], material processing is performed by application of two heat sources, one of which is laser radiation. The other source can be electric arc or plasma. Here, the impact of each of the heat sources on the material being processed is of a pulsed nature, and the impact of these pulses is mutually synchronized. A number of technological operations (including welding, brazing, cutting, engraving, alloying, quenching, etc.) can be performed by the same process.

The disadvantage of this process is the need for pulse generators and their synchronizing device, whereas application of continuous impact of both the heat sources on the material being processed does not require such sophisticated additional equipment.

To eliminate the above drawback a torch is proposed in the patent [10], which combines the design elements of torches for laser and for plasma welding. Laser radiation is directed to the objective lens so that its axis coincides with that of plasma-arc torch. The laser beam passes through a flat (in the form of a washer) or conical electrode (cathode) through a longitudinal coaxial hole made in it, with the diameter somewhat larger than that of a focused laser beam (see Figure 1, a). The plasma-forming nozzle is located under the cathode so that the laser beam passes through its axis. Similar to standard plasma-arc torch, the gas is passed through a chamber with cathode and nozzle in its lower part. Laser beam passing through such a cathode heats it to facilitate electron emission, and acts on the item being welded (anode), and also interacts with arc plasma, thus increasing the energy density on the item.

A small design disadvantage of proposed in [10] torch for laser-plasma welding is presence of a tubular cathode, the outlet of which should be such that focused laser radiation flowed out of it. This increases the plasma arc transverse size, and lowers the resistance of the cathode proper because of its erosion in service. Its periodical sharpening becomes more difficult.

In laser-plasma torch of a better design, focused laser radiation passes by a group of electrodes located about its axis at a sharp angle to the torch central axis (see Fig. 1, b) [11]. In this hybrid welding process, the focused laser radiation axis coincides with the torch axis, and is normal to the plane of parts being welded. Electrode axes are located on the generatrix of a cone, the vertex of which falls on the torch central axis near the edge of the nozzle, forming the plasma, and the cone proper is inverse relative to the torch outlet part. Laser-plasma welding occurs at running of electric arc between the electrode (at least, one) and part being processed. Such a discharge forms the plasma by blowing gas through outlet nozzle. Plasma, leaving the nozzle, forms a hybrid laser-arc discharge together with laser radiation.

The disadvantage of the above design is the possibility of hitting the optical path along which the laser beam, reflected from weld pool, is fed. There is a high probability of failure of optical elements of the path. Particularly dangerous in this respect is the case of welding aluminium alloys, because of high values of their coefficient of laser radiation reflection.

Figs. 3, a and 4 give the designs of HLPW heads, in which the radiation focusing system and plasma torch (plasmatron) are used separately. The main advantage of such structures is the possibility of hybrid welding realization with application of available welding equipment, i.e. without the need to create specialized integrated hybrid plasmatron (for instance, the one given in Figs. 2 and 3, b). The disadvantages of designs with separate components of hybrid process include rather high angles of inclination of plasmatron electrode axis that lowers its application effectiveness.

Therefore, an urgent task is application of such a method of laser-plasma welding, at which the electric arc, formed between the electrode (one as a minimum) and processed part, generates plasma due to gas blowing through the outlet nozzle, while laser radiation emitted through the same nozzle, promotes inducing laser-arc discharge. Here, the angle of inclination of focused laser radiation axis should be selected such as to eliminate the hazard of reflected radiation hitting the optical surfaces, 
and the angle between the axes of the electrode and focused radiation should be the minimum possible one. Summing-up the above-said, one can say that the best schemes of laser-plasma welding are those shown in Fig. 5.

Another comparatively recent technological development is the hybrid laser-plasma process with powder filler material [17]. Schematic of such a process realization is given in Fig. 6. Its main advantages are elimination of energy losses associated with heat removal into the filler (or electrode) wire, and improvement of the conditions of powder filler melting due to their low heat conductivity. These advantages enable raising the welding speed without increasing the heat input.

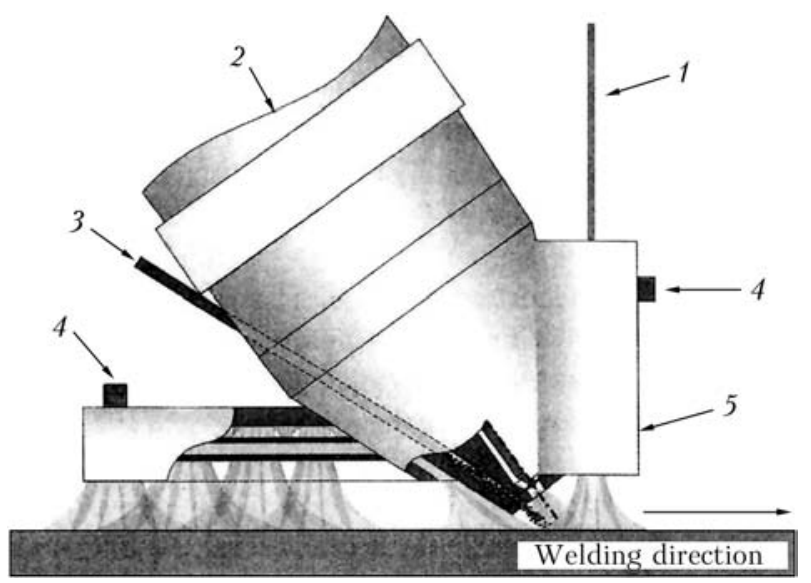

Fig. 6 Schematic of HLPW with transferred plasma arc and powder filler [17]:

1 - laser radiation; 2 - plasma gas; 3 - powder with carrier gas; 4 - shielding gas; 5 - tube through which radiation is fed.

\section{Removal of the Oxide Film during Hybrid Welding of Aluminum Alloys}

One of the most important features of laser-plasma welding is the possibility of removal of $\mathrm{Al}_{2} \mathrm{O}_{3}$ oxide film in aluminium alloy welding due to the so-called cathode cleaning. The cathodic cleaning process consists in breaking the refract tory oxide film within the zone of the cathode spot, moving chaotically over the aluminium alloy surface without its melting. According to [18], the mechanism of such cleaning consists in the following. At ion bombardment the kinetic energy is impacted to oxide film molecules, which is transformed into mechanical energy of vibrations. If this energy is greater than that of $\mathrm{Al}_{2} \mathrm{O}_{3}$ molecule dissociation, the latter decomposes into atoms, which leave the surface.

In practice, the above effect became widely applied in aluminium alloy welding. So, welding of external fuel tanks of the Space Shuttle, various beam structures, etc. was performed with application of cathode cleaning at plasma-arc welding by pulses of different polarity [19]. Attempts at removing the oxide film were also made in laser welding of aluminium-based alloys [20, 21]. This task is particularly urgent in laser welding of car bodies from aluminium alloys [22]. However, in the opinion of authors of $[12,23]$, HLPW is the most effective in welding these alloys with simultaneous cleaning of the edges being joined. It allows sound cleaning to be performed even at quite high (up to $300 \mathrm{~m} / \mathrm{h}$ ) welding speeds.

\section{Comparison of Laser, Arc (Plasma) and Hybrid Welding Features}

A number of studies devoted to comparison of the features of laser, arc (plasma) and hybrid welding should be noted. In [24] the prospects for application of plasma, consumable and nonconsumable electrode arc in inert gas for hybrid welding are studied. In [25] the differences of hybrid laser-TIG welding processes at application of $\mathrm{CO}_{2^{-}}$and $\mathrm{Yb}$ :YAG-lasers in them, i.e. radiations with wave length of 10.6 and $1.03 \mu \mathrm{m}$, respectively, are analyzed. It is shown that with reduction of wavelength, laser radiation absorption and refraction in arc plasma decreases. In results of laser (with $\mathrm{CO}_{2}$-laser radiation) and hybrid $\left(\mathrm{CO}_{2}\right.$-laser $\left.+\mathrm{TIG}\right)$ welding of T-joints in fabrication 
of load-carrying stainless steel frames are compared. Here, the good prospects for the hybrid process are shown. Now, in welding of zinc-plated steel sheets for manufacture of car bodies preference is given to Nd:YAG-laser radiation [27].

Quite a lot of attention was given in many studies to metallographic features and strength characteristics of welded joints produced by laser, hybrid or other process (for instance, [28-30]). Residual stresses in weld metal were studied, that is particularly important in welding titanium alloys for aircraft industry applications [31]. New mechanisms of hybrid processes [32] and their technological features were investigated. Among the latter the following studies should be noted: studying the influence of shielding gas pressure on laser-MIG welding [33]; the results of laser-arc welding of titanium alloys [34]; hybrid welding by Nd:YAG-laser radiation and MIG/MAG process [35]; laser-microplasma welding of metal filters using stainless filler wire [36]. New techniques were developed. In [37] hybrid laser-TIG welding of stainless steel 304 with application of rotating double-focus of the laser beam was proposed. In [38] the influence of relative position of laser radiation focus and consumable electrode arc on weld formation in hybrid welding was studied.

Of special interest are various technological and design recommendations given in the works on hybrid welding. For instance, to increase penetration depth it is recommended to use short-focus optics, which allows the size of the focal spot to be reduced (Fig. 7) [39]. At application of fiber-optic lasers for hybrid welding, increase of radiation power and reduction of focal spot size increase the process effectiveness, similar to application of other laser types. In this case, increase of radiation power lowers the welding cur- rent, but it does not affect arc voltage [40]. Electric arc placing first along the welding direction in the hybrid process can lead to a certain increase of penetration depth and reduction of weld width (Fig. 8). Influence of the distance between focused radiation and the arc on penetration depth was also established [41]. It is shown that the hybrid effect is lost if this distance is greater than 5-7 mm (Fig. 9) [42].

An important aspect of hybrid welding is allowing for liquid metal pressure and arc pressure on weld pool (Fig. 10). Balance of these pressures and surface tension forces prevents pool liquid metal flowing out and allows performance of «unsupported» hybrid welding, i.e. without application of process backing, which makes the processes of welding and subsequent treatment more complicated. Note that remelted metal volume in hybrid welding usually is greater than in laser welding (Fig. 11). This circumstance can promote increase of penetration depth in welding butt joints with a gap (Fig. 12) between the edges being welded due to this gap filling by liquid metal [43].

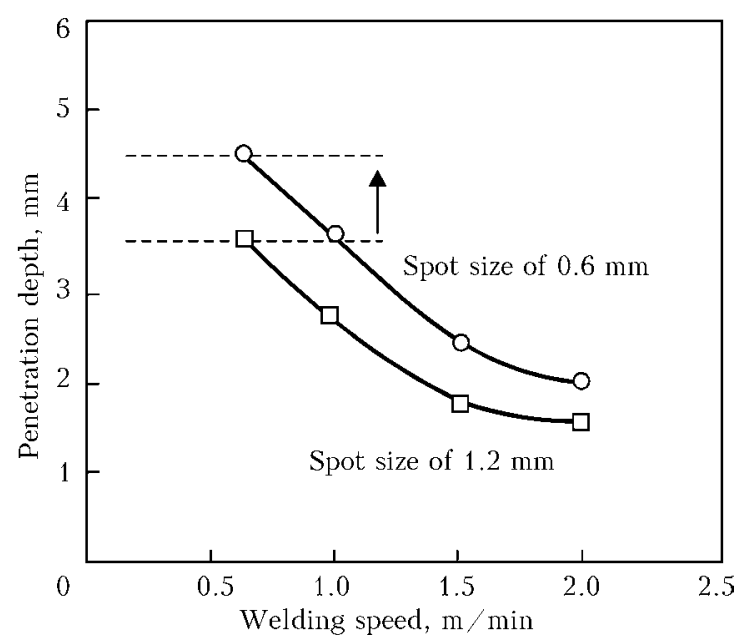

Fig. 7 Influence of size of laser radiation focal spot on penetration depth of SUS304 steel plate $(\delta=5 \mathrm{~mm})[39]$ ( $2 \mathrm{~kW}$ power, shielding gas is argon). 


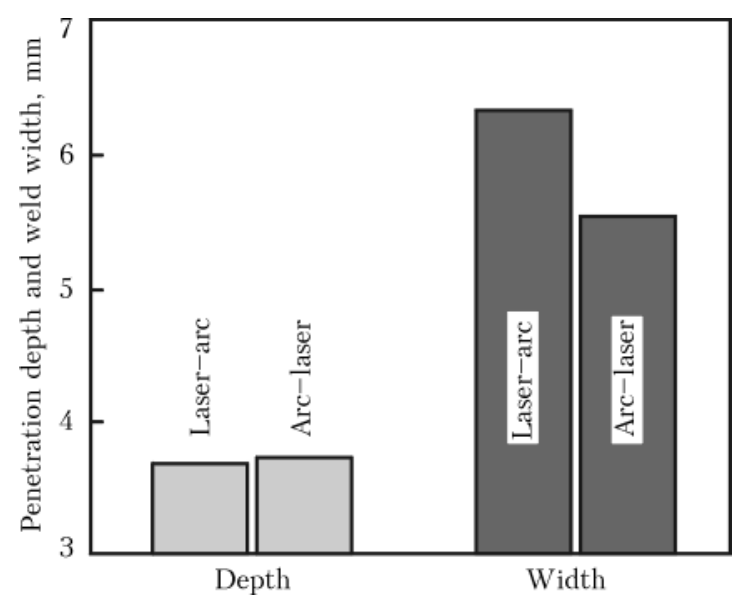

Fig. 8 Influence of relative position of $\mathrm{CO}_{2}$-laser beam or GMA arc on penetration depth and weld width in hybrid welding of HSLA-590 steel [41].

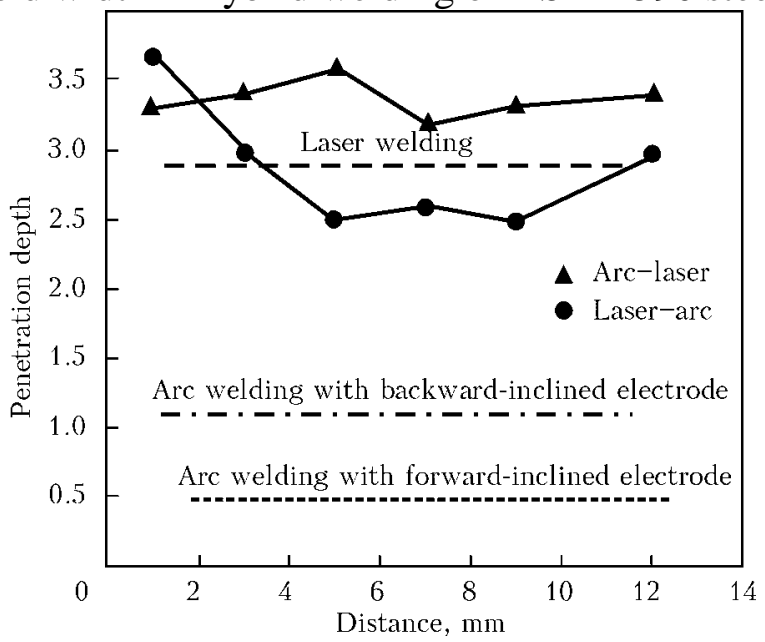

Fig. 9 Influence of distance between Nd:YAG-laser beam and nonconsumable electrode arc, as well as their relative position, on penetration depth of stainless steel 304 [42].

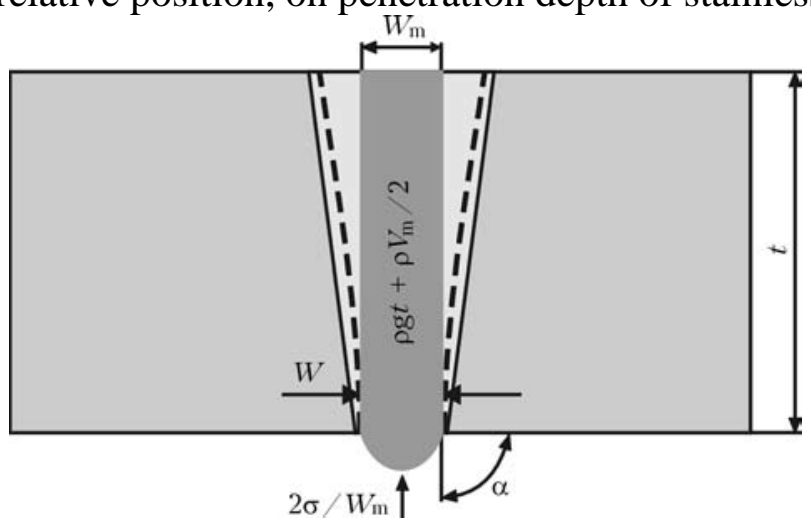

Fig. 10 Pressure balance in weld pool root part [6].

In HLPW the laser beam and the plasma arc should be positioned as close as possible to the item being welded. One of the variants of satisfying this condition is application of a tubular cathode, through which focused laser radiation is passed (see Fig. 1, a) [1, 44]. Another variant is application of a cathode inclined at a certain angle (see Fig. 4). This angle usually is rather large (for instance, about $\left.45^{\circ}[44,45]\right)$ that weakens the effect of plasma. Works [46-48] demonstrate the urgency of reducing the angle of inclination of the cathode to item surface and the angle between the cathode and laser beam axis.

The main objectives of HLPW include not only arc heating of item metal to increase absorptivity, but also modifying the welding thermal cycle to lower the rate of cooling after welding [45]. This enables lowering the content of brittle structures prone to fracture in service. Moreover, presence of plasma component allows lowering the requirements to the quality of assembly of the butts being 
welded compared to laser welding. These requirements, however, are higher compared to laser-TIG welding [49].

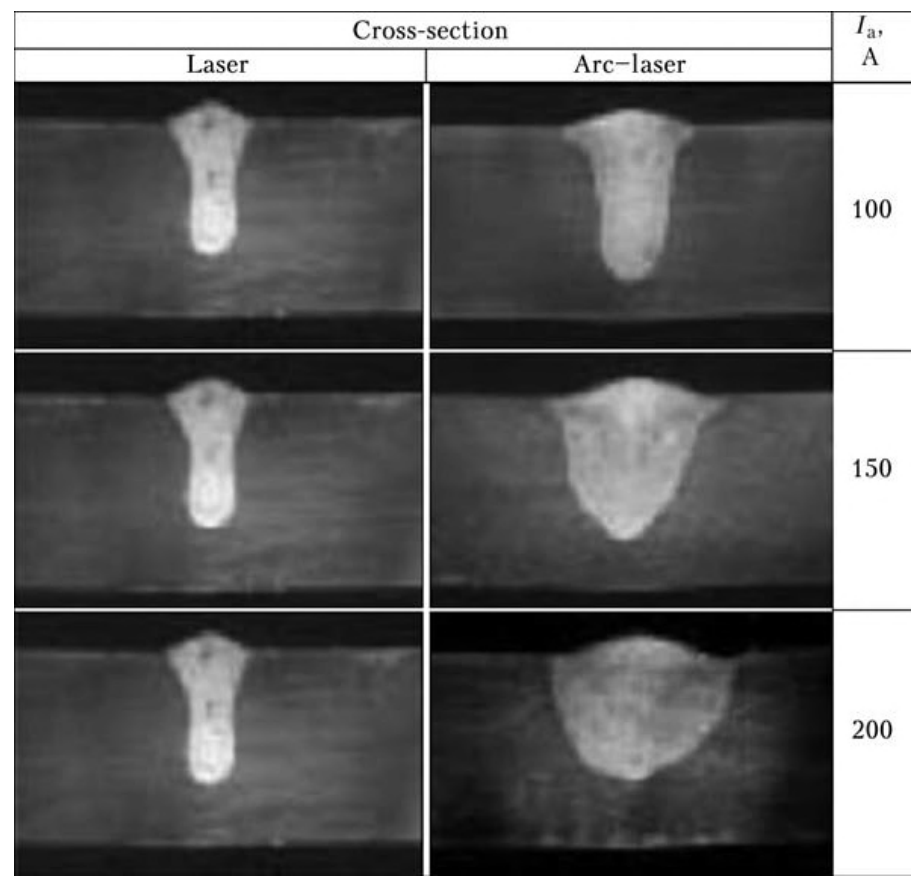

Fig. 11 Comparison of penetrations in austenitic stainless steel AISI304 $(\delta=5 \mathrm{~mm})$ made by Nd:YAG laser $(\mathrm{P}=1.7 \mathrm{~kW})$ and by hybrid process in combination of this laser with nonconsumable electrode arc at speed of $10 \mathrm{~mm} / \mathrm{s}$ at different welding currents [42].

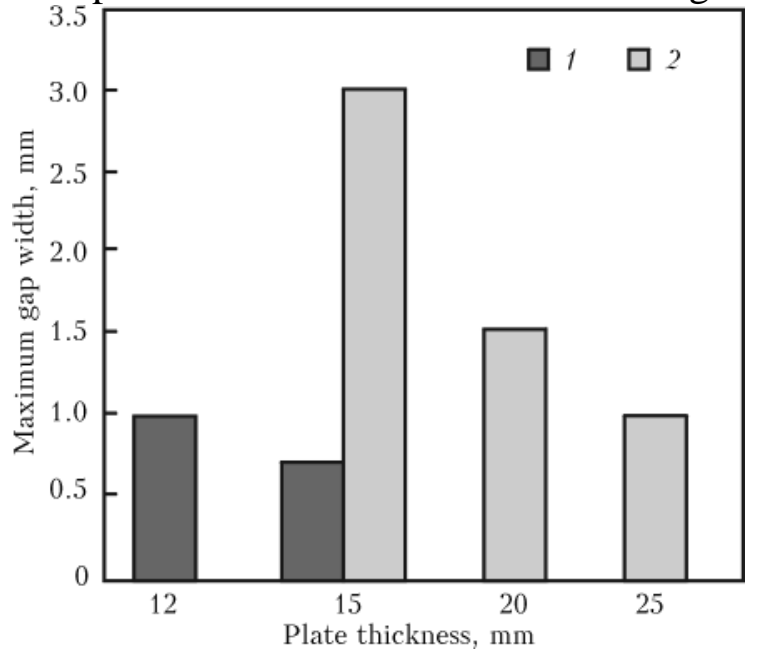

Fig. 12 Dependence of maximum gap width between the edges of plates being welded on their thickness and position in space: 1 - downhand; 2 - horizontal welding [43].

In [47] experiments on laser-plasma welding of such materials as low-carbon and stainless steel, titanium and aluminium alloys $0.6-2.0 \mathrm{~mm}$ thick are described. Used for this purpose was radiation of $\mathrm{CO}_{2}$-laser of up to $400 \mathrm{~W}$ power and up to $50 \mathrm{~A}$ welding current. It is established that laser-plasma process can prevent formation of «humps» in high-speed welding of thin sheets. Tolerances for the gap between the butt edges are equal from 0.15 up to $0.50 \mathrm{~mm}$ at welding speed of $2 \mathrm{~m} / \mathrm{min}(\sim 33 \mathrm{~mm} / \mathrm{s})$.

According to predictions given in [50], hybrid welding will allow increasing the efficiency by $300-500 \%$ at cost reduction by $55 \%$. Here, the consumables cost will be reduced approximately by two times, that will allow lowering the welding process cost by approximately a quarter. Another important aspect is smaller width of welds produced by the hybrid process, compared to welds made by arc processes that reduces the structure metal intensity. 


\section{Conclusion}

This leads to the conclusion that the prospects for industrial application of hybrid laser-plasma welding are associated with its cost and process advantages. Cost advantages consist in partial (up to 50\%) replacement of quite expensive laser power by much less expensive plasma power, as well as in lowering of power inputs into the process due to the possibility of filler wire replacement by the respective powder or total elimination of filler material. Process advantages consist in reduction of residual thermal deformations, lowering of requirements to edge preparation (including the possibility of edge welding with a variable gap width), ability to perform cathodic cleaning of aluminium alloys directly during their welding, increase of penetration depth, and increase of process efficiency several times compared to plasma welding and approximately by $40 \%$, compared to laser welding. Introduction of laser-plasma welding is capable of changing the modern attitudes of technologists to the welding process and those of designers - to welded structure design. Industrial application of laser-plasma welding is associated, primarily with solving the tasks of joining titanium and aluminium alloys, as well as stainless steels in the thickness range of 0.3-15.0 $\mathrm{mm}$.

\section{Acknowledgement}

This work is supported by the Recruitment Chinese Program of Foreign Experts No.WQ20124400119, Guangdong Innovative Research Team Program No.201101C0104901263, Science and Technology Project of Guangdong province No.2015A050502039, Science and Technology Project of Guangdong province No.2016B050501002.

\section{References}

[1] I. V. Krivtsun, Combined Laser-Arc Processes of Treatment of Materials and Devices for their Realization. Syn. Thesis Dr. Techn. Sci. Degree. Kiev: PWI, 2002, 393.

[2] W. M. Steen, M. Eboo, Arc Augmented Laser Welding. Metal Constr. 11(7) (1979) 332-335.

[3] W. M. Steen, Arc Augmented Laser Processing of Materials. J. Appl. Phys. 51(11) (1980) 5336-5641.

[4] W. M. Steen, Methods and Apparatus for Cutting, Welding, Drilling and Surface Treating. Pat. 1547172 Great Britain. Int. Cl. B23 K 26/00, 9/00. Publ. 06.06.79.

[5] C. Bagger, F. O. Olsen, Review of Laser Hybrid Welding. J. Laser Appl. 17(1) (2005) 2-14.

[6] D. Petring, C. Fuhrmann, N. Wolf, et al. Progress in Laser-MAG Hybrid Welding of High Strength Steels of up to $30 \mathrm{~mm}$ Thickness. In: Proc. of ICALEO (Orlando, Fl, USA, 2007), 2007, 300-307.

[7] K. Shibata, H. Sakamoto, T. Iwasa, Laser-MIG Hybrid Welding of Aluminium Alloys. Weld. World, 50(1/2) (2006) 27-34.

[8] Laser Technology of Trumpf Company. http:// www.trumpf-laser.com

[9] Products of STA IRE-Polus. http://www.ntoire- polus.ru

[10]I. S. Dykhno, I. V. Krivtsun, G. N. Ignatchenko, Combined Laser and Plasma Arc Welding Torch. Pat. 5700989 USA. Int. Cl. B23K 26/00, 10/00. Publ. 23.12.97.

[11]I. Dykhno, G. Ignatchenko, E. Bogachenkov, Combined Laser and Plasma-Arc Processing Torch and Method. Pat. 6388227 B1 USA. Publ. 14.05.2002.

[12]I. V. Krivtsun, V. D. Shelyagin, V. Yu. Khaskin, et al. Hybrid Laser-Plasma Welding of Aluminium Alloys. Paton Weld. J. 5 (2007) 36-40. 
[13]R. P. Walduck, Enhanced Laser Beam Welding. Pat. 5866870 USA. Int. Cl. B23 K 10/00, 26/00. Publ. 02.02.99.

[14] C. H. Kim, Y. H. Ahn, J. H. Kim, $\mathrm{CO}_{2}$ Laser-Microplasma Arc Hybrid Welding for Galvanized Steel Sheets. Trans. Nonf. Met. Soc. China, 21(1) (2007) 47-53.

[15]I. V. Krivtsun, A. I. Bushma, V. Yu. Khaskin, Hybrid Laser-Plasma Welding of Stainless Steels. Paton Weld. J. 3 (2013) 46-50.

[16]D. Petring, Laser Material Machining Using Hybrid Processes. Pat. WO2003089185 A1 USA. Publ. 30.10.2003.

[17]K. Stelling, M. Lammers, H. Schobbert, et al. Qualification of Nd:YAG and $\mathrm{CO}_{2}$ Laser Plasma Hybrid Welding with Filler Material Powder. Weld. Cutt. 5(6) (2013) 330-334.

[18]B. E. Paton, V. S. Gvozdetsky, D. A. Dudko, et al. Microplasma Welding. Kiev: Naukova Dumka, 1979.

[19]Ch. Kexuan, L. Heqi, L. Chunxu, Cathodic Cleaning in Variable Polarity Plasma Arc Welding of Aluminum Alloys. China Weld. 2 (2003) 168-170.

[20]Z. Bingkun, Study of Processing Parameters of $\mathrm{CO}_{2}$-Laser Welding on Aluminum Alloys. Chinese J. Laser. 2 (2000) 183-186.

[21]Q. Junfeng, Z. Dongyun, X. Rongshi, et al. Joint Performance of $\mathrm{CO}_{2}$ Laser Beam Welding 5083-H321 Aluminum Alloy. China Weld. 2 (2007) 40-45.

[22]S. Yu, D. Fan, J. Xiong, J. Chen. $\mathrm{CO}_{2}$-laser Welding of 5A06 Aluminum Alloy Plates with Different Thicknesses. Trans. Nonf. Met. Soc. China, 3 (2006) 1407-1410.

[23] V. Yu. Khaskin, Development of Laser Welding of Aluminium Alloys at the E.O. Paton Electric Welding Institute (Review). Paton Weld. J. 5 (2013) 51-55.

[24]C. Bagger, F. O. Olsen, Comparison of Plasma, Metal Inactive Gas (MIG), Tungsten Inactive Gas (TIG) Processes for Laser Hybrid Welding. In: Proc. of 22nd ICALEO (Jacksonville, Fl, USA, 13-16 Oct. 2003), 2003, 11-20.

[25]W. Shikai, X. Rongshi, Y. Wuxiong, et al. Characteristics Comparison of Laser-TIG Arc Interaction Using High Power $\mathrm{CO}_{2}$ - and Yb:YAG-laser. Chinese J. Laser. 10 (2010) 2667-2671.

[26] W. Shikai, X. Rongshi, C. Kai, $\mathrm{CO}_{2}$-laser Welding and $\mathrm{CO}_{2}$-laser-TIG Hybrid Welding of Thin Walled Stainless Steel Butt Joint from the Base Plate Side. Electromach. Mould. 6 (2009) 29-33.

[27]S. Katayama, M. Mizutani, T. Tarui, et al. Monitoring and Phenomena Observation during YAG-laser Lap Welding of Zn-coated Steel Sheets. J. Lanzhou University of Technology, 4 (2004) 31-36.

[28]L. Liming, G. Song, J. Wang, G. L. Liang, Microstructure and Mechanical Properties of Wrought Magnesium Alloy AZ31B Welded by Laser-TIG Hybrid. Trans. Nonf. Met. Soc. China, 14(3) (2004) 550-555.

[29]X. Zhang, W. Chen, C. Wang, et al. Microstructures and Toughness of Weld Metal of Ultrafine Grained Ferritic Steel by Laser Welding. J. Mater. Sci. Tech. 6 (2004) 755-759.

[30]W. Wenquan, S. Daqian, K. Chungyan, Macrostructural and Microstructural Features of 1000 MPa Grade TRIP Steel Joint by $\mathrm{CO}_{2}$-laser Welding. China Weld. 2 (2008) 1-7.

[31]H. Xiaodong, Z. Jianxun, P. Zuo, et al. Test of Residual Stress in Laser Beam Welding and TIG Welding Joints of Aeronautical Titanium Alloy Plate. Weld. Join. 10 (2003) 26-29.

[32]X. Yuan, S. Yonglun, H. Kunping, New Development of Mechanisms of Laser-TIG Arc 
Hybrid Welding. Weld. Join. 12 (2008) 21.

[33] Y. Chen, Z. Lei, L. Li, et al. Influence of Shielding Gas Pressure on Welding Characteristics in CO2-laser-MIG Hybrid Welding Process. Chinese Opt. Lett. 1 (2006) 33-35.

[34]C. Li, L. Xiaoyan, H. Dingyong, et al. Laser-Arc Hybrid Welding of Titanium Alloy. Weld. Join. 7 (2009) 60-64.

[35]L. Zhen, Q. Guoliang, L. Shangyang, Development of YAG laser-MIG/MAG Arc Hybrid Welding Technology. Weld. Join. 9 (2005) 9-12.

[36]W. Fuzuo, H. Jianping, X. Feng, Study on Stainless Steel Screen Mesh Welding Using Microplasma Arc Welding. Hot Work. Tech. 1 (2010) 128-130, 133.

[37] L. Xiaohui, W. Su, X. Caiyun, 304 Stainless Steel Rotary Twin-Focus Laser-TIG Hybrid Welding. J. Beijing Univ. Aeronaut. Astronaut. 4 (2008) 431-434.

[38] Zh. Gao, J. Huang, Y. Li, Effect of Relative Position of Laser Beam and Arc on Formation of Weld in Laser-MIG Hybrid Welding. Trans. China Weld. Inst. 12 (2008) 69-73.

[39] T. Ishide, S. Tsubota, M. Watanabe, Latest MIG, TIG Arc-YAG Laser Hybrid Welding Systems for Various Welding Products. In: Proc. of 1st Int. Symp. on High-Power Laser Macro (Osaka, 2002), 2002, 347-352.

[40] C. Roepke, S. Liu, S. Kelly, et al. Process Monitoring and Macrostructure Examination of Low Laser Power Hybrid Gas Metal Arc Welding on A36 Steel: IIW, 2010, Doc. IV-1030-1038.

[41]Z. Liu, M. Kutsuna, Metallurgical Study on Laser-MAG Hybrid Welding of HSLA-590 Steel. In: Proc. of Laser Materials Processing Conf. (Miami, Fl, USA, 2005), 2005, 127-133.

[42] Y. Naito, M. Mizutani, S. Katayama, Observation of Keyhole Behavior and Melt Flows during Laser-Arc Hybrid Welding. In: Proc. of ICALEO (Jacksonville, USA, 2003), Sect. A, 2003, 159-167.

[43] Y. Yuan, M. Wouters, J. Powell, et al. Optimization Research on Laser-MIG Composite Welding for Rear Axle Steel Plate. Autom. Tech. 1 (2008) 54-57.

[44] I. V. Krivtsun, M. I. Chizenko, Principles of Calculation of Laser-Arc Plasmatrons. Autom. Weld. 1 (1997) 16-23.

[45] P. Kah, A. Salminen, J. Martikainen, Laser-Arc Hybrid Welding Processes (Review). Paton Weld. J. 6 (2010) 32-40.

[46] I. V. Krivtsun, A. I. Bushma, V. Yu. Khaskin, Laser-Plasma Welding Of Stainless Steels and Aluminium Alloys. Dopovidi NANU, 3 (2013) 76-82.

[47] V. N. Sidorets, A. I. Bushma, V. Yu. Khaskin, Prospects of Application of Hybrid Laser-Plasma Welding of Stainless Steels in Machine-Building. Visnyk DDMBA, 28(3) (2012) 244-246.

[48] V. D. Shelyagin, A. M. Orishich, V. Yu. Khaskin, et al. Technological Peculiarities of Laser Micro-Plasma and Hybrid Laser-Microplasma Welding of Aluminium Alloys. Paton Weld. J. 5 (2014) 33-39.

[49] R. P. Walduck, J. Biffin, Plasma Arc Augmented Laser Welding. Weld. Met. Fab. 4 (1994) 172-176.

[50] K. Paul, F. Ridel, Hybrid Laser Welding - Joining the Efforts. Fhoton. 1 (2009) 2-5. 